\title{
Analysis on the Application of Big Data in Classroom Teaching
}

\author{
Dan Zhang \\ Jilin Radion and TV University, Changchun, Jilin, 130021
}

Keywords: Big Data, Classroom Teaching, Application Method

\begin{abstract}
The development of the Internet, the Internet of Things and cloud computing has driven the intelligent and digital construction of the society. The era of big data has a direct impact on our production and life. Information explosion and data sharing have also led to the innovation of university courses. Do a good job in the advantages of big data in the curriculum reform of colleges and universities, build a teaching innovation platform with big data, serve the teaching and research of colleges and universities, and inject vitality into the sustainable and stable development of colleges and universities. Focusing on the innovation of college curriculum under the era of big data is an important aspect of the future development of colleges and universities.
\end{abstract}

\section{Introduction}

Big data, simply understood is a large amount of data and massive data. As early as the mid-19th century, people began to quantify the data. With the development of the information society, computer network technology was applied to our daily life, and the Internet was the carrier. The informatization construction is deep, and the information-related big data concept is also more prominent, and it is applied to the construction of college courses. The massive electronic data supported by big data is scientifically integrated, and the guiding results are obtained to help college education. Big data is generated in network production. Different fields have different requirements for data. For big data, although China's definition is not clear, its four advantages have been agreed. They are large capacity, high speed, diversity and value. Big data technology realizes the massive data, realizes the effective mining of the massive data value, uses the computer as the operation carrier, and uses distributed computing architecture, cloud computing distributed processing technology, distributed database and cloud storage, virtualization technology. With the assistance of the integration analysis of big data, it provides scientific guidance for data management. In recent years, as big data has become a popular vocabulary in the Internet information technology industry, education has gradually been recognized as an important application area where big data can make a difference. Some people boldly predict that big data will bring revolutionary changes to education.

\section{The significance of the application of big data in classroom teaching}

The ultimate goal of big data behavior analysis is to improve student achievement. The number of students with excellent academic performance plays a vital role in social development. However, most people now only focus on the results, using the results as the sole criterion for evaluating students, so that a series of important information in homework and exams is ignored. By analyzing big data, we can discover these important information and use them to provide personalized service to improve student achievement. Evaluate and analyze student behavior through technical aspects to enhance teaching activities. It is no longer just relying on experience to evaluate, but on the basis of data. In this way we will not rely solely on subjective perception or empiricalism. Through a large number of data summarization, we can find out the rules of teaching activities, so as to better improve and optimize the teaching process. It helps us to improve students' performance and improve their performance by exploring the inner relationship between students' behavior and their changes and exploring the more intrinsic characteristics of students.

In the era of big data, educational researchers can really approach students and understand students. Through the recording of immediate behaviors and phenomena, the most powerful 
information big data technology can be obtained. Based on these most authentic and personalized student information, teachers can teach students in a targeted manner and truly achieve student-centeredness. By exploring the classroom learning process, you can understand the students' undergraduate study. It really reduces the student's academic burden and also makes it possible for more efficient learning.

Through data mining and learning analysis, the teacher timely adjusted the learning strategy and changed the educational management mode after obtaining the student's information. [2] Traditional education is mostly carried out by the education authorities and educators through the learning, summarization and inheritance of teaching experience. However, some experiences are not scientific, and common sense often affects people's judgment. In the era of big data, if we want to formulate a more realistic education policy and teaching strategy, it is the best way to analyze the educational data. It can dig out the most in-depth situation in line with the actual situation of students and the actual teaching, which is to build learners. The empirical model establishes the learner behavior model, constructs the learner knowledge model, constructs the domain knowledge model, and constructs the learner's file, so that the improved teaching strategy can be traced.

\section{Big Data Challenges in Classroom Applications}

Although after a series of educational reforms, it is still the class teaching and group teaching. The application of big data makes the time and space of classroom teaching no longer restricted, and transforms the traditional one-to-many teaching mode into a one-on-one personalized course. However, in the actual personalized learning, many problems are also commonly displayed. Although students can use the Internet media such as computers and mobile phones, they can be used anytime, anywhere, and repeatedly. Online teaching is increasingly becoming an important part of classroom teaching. Teaching videos, but also exposed the shortcomings, so that students can not continue to listen to this concept, the learning efficiency is also greatly reduced, the self-discipline of students has become a major problem in online learning. While big data applications enable students to do test questions online and interact with teachers online, there is a lack of discipline in face-to-face teaching. For students who lack self-control, this learning style becomes a lazy shelter. In today's big data applications, various educational institutions are launching their own online learning platforms, but the late services can't keep up, making this excellent data resource wasted.

With the advancement of big data education, the Internet has provided students with a large number of learning resources, which provides convenience for students to answer questions. However, this has also become a source of problems for big data applications to education. Traditional textbooks require a process from author writing to textbook publishing. Teachers' familiarity with textbooks requires a process. In addition, traditional classroom professors need a process, which leads to the lag of knowledge point updating and the changing social development needs. Adaptation has caused students to learn content that is out of touch with reality, and learning is not used. Although teachers constantly update the teaching content to meet the students' needs for knowledge during the course of the class, the speed of teacher knowledge update is still unable to catch up with the impact of the big data era. Teachers often encounter contradictions in the classroom with the latest research results. The knowledge given is out of line with the actual age of the students. The knowledge given is inconsistent with the actual understanding and proficiency of the students, which makes modern teachers face embarrassing situations. Big data brings more challenges to traditional classroom teaching content, and requires that teaching content be constantly changing with the times to adapt to the development of the times.

\section{Guiding strategies for college curriculum innovation construction under the big data environment}

The big data era brings the first change in the environment, and the environmental change has led to the diversification of the trend of thought. In the big data environment, the original time and 
space limitations are broken, and the social value trend is more diverse. Big data thinking has also realized the multi-application in the curriculum construction of colleges and universities. The era of big data has brought about an innovative elective model. Based on the credit system implemented by colleges and universities, big data has realized the autonomy of course selection. Based on the fact that most students don't know enough about the school curriculum, big data thinking is used to select courses, and students can develop an intelligent course selection system. Students can have a more comprehensive understanding of the curriculum system. The number of lecturers, class hours, course value, and curriculum system can be greatly improved. The data is directly displayed, and students have greater autonomy in class selection. Big data thinking also realizes the individualized teaching and training of students. The big data mining technology is combined with the course content. The online learning system indicates the learning direction for students and formulates specific personalized learning plans. The Big Data Support System evaluates personal development and analyzes the results to produce an excellent curriculum. Schools can also integrate data based on teaching feedback, predict the implementation of the course, and provide students with a more professional and targeted list of courses.

The big data environment has brought about the diversification of online teaching carriers. Therefore, the curriculum construction of colleges and universities should give full play to the advantages of the multimedia teaching mode, and encourage teachers to innovate the curriculum teaching mode on the premise of perfecting the basic conditions of teaching. Through the comprehensive teaching presentation of texts, pictures and audio and video materials, the transmission of richer information volume is more conducive to the improvement of students' thinking ability, imagination ability and information technology literacy. The network teaching platform of multimedia and big data has also become the carrier of communication and interaction under the class of teachers and students. Students can share the confusion in learning on the platform, and the teachers answer questions and provide personalized answers. Teachers can also share the latest curriculum knowledge and research information, so that students can obtain effective learning guidance and expand their learning horizons. The big data environment also puts forward specific requirements for the innovation of teaching methods. How to grasp the attention of students in the era of big data and mobilize the enthusiasm of students to explore the curriculum, it is necessary for college teachers to pay attention to the learning experience of students and to innovate teaching methods. In the course construction of colleges and universities, try the case teaching method, scientific research analysis method, scenario simulation method, group cooperation inquiry method, practice practice training method, etc., and use various teaching methods flexibly to stimulate students' attention to the curriculum and let students learn. Plan design, communicate expression, organize and coordinate, study problems and solve problems, fully realize their own initiative, and truly participate in the course study. The traditional course teaching is transformed into the complement of classroom teaching and extracurricular network teaching. Laptops, smart phones, self-learning and guiding learning through mobile terminal devices, realize the barrier-free communication between teachers and students, and bring the breadth and depth of university curriculum teaching. Promotion

The innovative application of big data in college courses is mainly reflected in the construction of information service platform. Introduce big data theory and technology in college curriculum teaching, establish university information service platform, collect and organize course information, analyze the development of course implementation based on data, publish the teaching information of the course, and build information sharing. The platform provides students with a more comprehensive information integration and retrieval service. The use of big data to establish an information-based teaching service platform, the collection of course information, course market applications and course projects in a big data environment to ensure the integrity and accuracy of the data. Actively collect relevant data on the talent market, do a dynamic market analysis of the value of the course teaching, and provide data guidance for the curriculum reform and curriculum adjustment of colleges and universities. Its two major data environments bring integrated analysis of data and information. A large amount of data is summarized and summarized, and the information is 
filtered and integrated by means of big data. As a data source used for later retrieval, the integrity and truth of the data system are ensured to the utmost. The third guarantees the timely and effective data information. The construction of the teaching information service platform of colleges and universities must always pay attention to the market employment situation and dynamic employment information, update the data regularly, and make specific adjustments and plans for the course content and system according to the market development dynamics. With the platform as the carrier, we will establish a perfect curriculum construction service website and use big data technology to guide the curriculum optimization.

\section{Conclusion}

The development of the era of big data is an inevitable trend. The arrival and rapid development of the era of big data is both a challenge and an opportunity for university curriculum innovation. In the context of the era of big data, colleges and universities must use big data technology to collect and analyze information when carrying out curriculum innovation construction. As a reference, we should do a good job in curriculum optimization and teaching guidance, so as to achieve the improvement of university students' learning autonomy. Let each student get a personalized curriculum plan, let the university curriculum innovation construction be implemented and achieve practical results.

\section{Acknowledgements}

Fund Project: In the 2018 year of Jilin Province Education Science "13th Five-Year Plan" (general planning) project "Strategy Research on the Effectiveness of Teaching under the Background of Big Data Vision", one of the results of the project phase, project leader: Zhang Dan No.: GH181087

\section{References}

[1] Yu Changzhi. Possible Turn of Education in Big Data Era[J].Jianghuai Forum, 2013(4).

[2] Liu Fengjuan. Review of Educational Application Research of Big Data[J]. Software Guide (Education Technology), 2014, Volume (G40-057): 47-51.

[3] Han Zhijun. A Brief Analysis of the Application of Big Data in Education[J]. Science and Technology Vision (Exploration and Controversy), 2013.

[4] Wu Feng. Visualization of educational big data research in China and its visual analysis[J].China Distance Education,1-8(2017-05-22).

[5] sXu Xiaodong, Zhao Xing, Xiao Hua, Yan Liang. The Application of Big Data in Undergraduate Teaching Evaluation__ Taking J University as an Example[J]. Higher Education Research, 2017, (01): 127-132 ( 2017-03-20). 